


\title{
LA TASACIÓN DE COSTAS EN EL PROCESO DE EJECUCIÓN HIPOTECARIA
}

\author{
Autor: Javier Ángel Fernández-Gallardo Fernández-Gallardo. ${ }^{1}$ \\ Secretario judicial del Juzgado Central de Instrucción n ${ }^{\circ} 5$ Audiencia Nacional. \\ Doctor en Derecho.
}

\section{Resumen}

En el proceso de ejecución hipotecario, tras la subasta y adjudicación del bien hipotecado, el ejecutado continúa siendo deudor no sólo de la parte del préstamo e intereses ordinarios no saldados con el valor de dicha adjudicación, sino de una importante cantidad correspondiente a los intereses moratorios y costas del proceso, que normalmente supera el 50\% del principal reclamado. En este estudio analizamos cómo tal exceso puede y debe ser mitigado mediante un adecuado control de las cantidades presentadas por el acreedor hipotecario en concepto de costas procesales, evitando así abusos amparados en la usual situación de rebeldía procesal del deudor hipotecario y consiguiente falta de impugnación.

Palabras clave: Tasación de costas, ejecución hipotecaria, secretario judicial.

\footnotetext{
${ }^{1}$ javier,fernández.gallardo@madrid.org
} 
The appraisal of costs in the proceedings of mortgage enforcement.

\begin{abstract}
In the mortgage foreclosure process following the auction and award of the mortgaged and property, the debtor continues to be liable not only for the ordinary interest loan, that is not settled for the value obteined with the award, but a significant amount of default interest and court costs, which typically exceed $50 \%$ of the principal claimed. In this study we analyze as such excess can and should be mitigated by proper control of the amounts presented by the mortgagee in respect of legal costs, thus avoiding abuses covered in the usual situation of procedural default of the mortgagor and subsequent lack of contest.
\end{abstract}

Keywords: appraisal of costs, mortgage enforcement, Court Clerk.

Recibido: 29-07-2013

Aceptado: 07-03-2014

\title{
1. INTRODUCCIÓN.
}

La ejecución hipotecaria, anteriormente regulada en los arts. 131 y ss. de la Ley Hipotecaria, Texto Refundido según Decreto de 8 de febrero de 1946 (BOE n ${ }^{\circ}$ $58,27.2 .1946$ ) (en adelante, LH), en la actualidad viene regulada en los arts. 681 y ss. Ley 1/2000, de 7 de enero, de Enjuiciamiento $\mathrm{Civil}^{2}$ (BOE n $7,8.2 .2000$ ) (en adelante, LEC), remitiendo este último artículo a las normas que regulan con carácter general la ejecución dineraria contenidas en el Tít. IV de Libro III, si bien con las especialidades que al efecto se regulan en su Cap. IV.

Resulta aplicable a este proceso, pues, lo dispuesto en el art. 575.1 LEC conforme al cual la ejecución «se despachará por la cantidad que se reclame en la

${ }^{2}$ La exposición de motivos LEC en su párrafo penúltimo de la exposición XVII dispone: «La nueva regulación de la ejecución sobre bienes hipotecados o pignorados supone un avance respecto de la situación precedente ya que, en primer lugar, se trae a la Ley de Enjuiciamiento Civil la regulación de los procesos de ejecución de créditos garantizados con hipoteca, lo que refuerza el carácter propiamente jurisdiccional de estas ejecuciones, que ha sido discutido en ocasiones; en segundo término, se regulan de manera unitaria las ejecuciones de créditos con garantía real, eliminando la multiplicidad de regulaciones existente en la actualidad; y, finalmente, se ordenan de manera más adecuada las actuales causas de suspensión de la ejecución, distinguiendo las que constituyen verdaderos supuestos de oposición a la ejecución (extinción de la garantía hipotecaria o del crédito y disconformidad con el saldo reclamado por el acreedor), de los supuestos de tercería de dominio y prejudicialidad penal, aunque manteniendo, en todos los casos, el carácter restrictivo de la suspensión del procedimiento». 
demanda ejecutiva en concepto de principal e intereses ordinarios y moratorios vencidos, incrementada por la que se prevea para hacer frente a los intereses que, en su caso, puedan devengarse durante la ejecución y a las costas de ésta». La cantidad prevista para estos dos conceptos, se fijará provisionalmente sin que pueda superar el $30 \%$ de la que se reclame en la demanda ejecutiva, sin perjuicio de su posterior liquidación. No obstante ello, y con carácter excepcional, la cantidad provisionalmente fijada para estos conceptos podrá exceder del límite indicado, si el ejecutante justifica que, atendiendo a la previsible duración de la ejecución y al tipo de interés aplicable, pudieran superar aquel límite.

Asimismo, y en relación exclusivamente a la vivienda habitual, la Ley 1/2013, de 14 de mayo, de medidas para reforzar la protección a los deudores hipotecarios, reestructuración de deuda y alquiler social (BOE $\left.\mathrm{n}^{\circ} 116,15.05 .2013\right)$, añade un apartado 1 bis al art. 575 LEC conforme al cual: «En todo caso, en el supuesto de ejecución de vivienda habitual las costas exigibles al deudor ejecutado no podrán superar el 5 por cien de la cantidad que se reclame en la demanda ejecutiva».

Por tanto conforme a la previsión efectuada por el legislador, las cantidades liquidadas en concepto de intereses y costas deberían ser ajustadas a las presupuestadas al efecto. Sin embargo la práctica diaria nos demuestra que nada más lejos de la realidad, pues habitualmente ambos conceptos superan con creces tal cantidad presupuestada, lo que evidencia que la parte ejecutante no se ajusta en sus liquidaciones a los parámetros que el legislador ha tenido presente a la hora de establecer el referido porcentaje. Circunstancia que se ve favorecida ante la frecuente situación de rebeldía procesal en la que se encuentra la parte ejecutada, y consiguiente falta de defensa técnica, unida a una práctica procesal que interpretando el principio de justicia rogada de forma rígida, apenas limita su control, en cuanto a la tasación de costas se refiere, a la comprobación de que la misma, conforme a la previsión contenida en el art. 394.3 LEC, no exceda la de la tercera parte de la cuantía del proceso, partiendo incluso de una cuantía fijada por el propio acreedor de la forma que más conviene a sus intereses.

Sin embargo, una adecuada interpretación de las normas reguladoras de la tasación de costas permite que éstas queden dentro de las cantidades presupuestadas a tales fines, tutelándose así de forma adecuada los intereses del deudor hipotecario, y garantizando al mismo una tutela judicial efectiva.

La condena en costas va dirigida a resarcir al vencedor de los gastos originados directa e inmediatamente en el pleito, entre los que se incluyen los honorarios del letrado, teniendo en cuenta que no se trata de fijar los honorarios derivados de los servicios del letrado respecto de su cliente que libremente eligió, sino de cuantificar un crédito derivado de la aplicación del principio procesal de vencimiento objetivo ${ }^{3}$. La minuta

${ }^{3}$ A modo de ejemplo AATS, $1^{\text {a }}$, 08.10.2007 (ROJ: ATS 13507/2007; MP Jesús Corbal Fernández); 08.01.2008 (ROJ: ATS 14/2008; MP Encarnación Roca Trias); 24.03.2009 (ROJ: ATS 4124/2009; MP Encarnación Roca Trias); 16.02.2010 (ROJ: ATS 1796/2010; MP Encarnación Roca Trias); y 25.05.2010 
incluida en la tasación debe ser una media ponderada y razonable no solo calculada de acuerdo a criterios de cuantía, sino además adecuada a las circunstancias concurrentes en el pleito, el grado de complejidad del asunto, la fase del proceso en que nos encontramos, la extensión y desarrollo de la demanda, el esfuerzo de dedicación y estudio exigido por circunstancias concurrentes, la complejidad y trascendencia de los temas suscitados en el procedimiento, la existencia de oposición, etc., sin que ello suponga que el abogado de la parte ejecutante no pueda exigir a su cliente el importe integro de los honorarios concertados con el mismo por los servicios profesionales ${ }^{4}$.

Hemos de recordar la importancia de la labor del órgano judicial, dentro del cual se incardina el secretario judicial ${ }^{5}$, en la medida en que su principal obligación reside en garantizar los derechos fundamentales y sociales de las personas, y de forma especial atender a la población más vulnerable. Junto al parámetro de la legalidad como vinculación técnica ineludible, debe insistirse en el de legitimidad, de forma que junto a la norma positiva deben ser de igual aplicación los principios y valores esenciales del ordenamiento jurídico plasmados en la Constitución (BOE $n^{\circ} 311,29.12 .1978$ ) (en adelante, CE), particularmente los de igualdad y justicia.

Ante situaciones de crisis económica deben reivindicarse las teorías garantistas que inciden en superar las estrechas visiones del principio dispositivo en el ámbito de la justicia civil, promoviendo asimismo la aplicación de las garantías constitucionales que

(ROJ: ATS 8201/2010; MP José Antonio Seijas Quintana), entre otras.

${ }^{4}$ AAP Las Palmas de Gran Canaria, Civil Sec. 5, 06.04 .2006 (ROJ: AAP GC 661/2006, MP: Pedro Joaquín Herrera Puentes).

${ }^{5}$ En este sentido Gimeno Sendra (1995, p. 255) entiende que «Si el secretario es algo más que un "órgano colaborador o auxiliar de la jurisdicción" (u Organ der Rechtspflege, como, al igual que el Ministerio Público, lo concibe la legislación orgánica alemana), si, junto con los jueces, forma parte integrante de la jurisdicción, las consecuencias prácticas que se derivan de esta naturaleza jurídica resultan evidentes: desde un punto de vista subjetivo u orgánico, al menos en los Estados compuestos, no pertenece a la denominada "Administración de la Administración de Justicia", sino que es Administración de justicia, por lo que merece ser ubicado dentro de los Consejos de la Magistratura u órganos de auto gobierno del Poder judicial, y, desde el objetivo, es evidente que, desde luego, no dicta actos administrativos, sino auténticos actos procesales susceptibles de incidir en el conjunto de garantías constitucionales que conforman el denominado derecho a un proceso debido, justo o con todas las garantías». Lorca Navarrete (1993, p. 223) afirma que «El secretario judicial por su carácter técnico superior es un cotitular del ejercicio de la función jurisdiccional en determinados aspectos, que no lo tipifica como juez de segunda clase, sino como colaborador necesario no del juez de primera, sino -lo que es más importante- del ejercicio de la función jurisdiccional que no posee categorías». Para Martín Ostos (1986, p. 70) «La conceptuación de éste como miembro integrante del órgano jurisdiccional, si a alguien aún le quedaba duda, es definitiva. No entorpece la labor del juzgador; por el contrario, coopera plenamente con él», consideraciones en las que insiste reiteradamente (1990, p. 35) (1991, p. 127) (1992, p. 805). En similar sentido se pronuncian Almagro Nosete (1990, p. 78); Jiménez de Parga (1985, p. 15); Morell Ocaña (1987, pp. 93 y 98); Prieto Castro (1984, p. 475) (1986, p. 351); RuizGiménez (1987, p. 14); Sainz de Robles (1987, p. 7); y Vázquez Sotelo (1985, p. 88), entre otros. Ossorio y Gallardo (1929, p. 147), considera que el secretario es un técnico altamente cualificado, razón por la que piensa que Magistratura, Judicatura y Secretariado constituyen una sola carrera. Comellas Salmerón (1954, p. 436), considera al secretario judicial como el más cercano colaborador del Juez y al que debería corresponder la función de sustituir a éste en su ausencia o necesidad. 
también deben regir este campo, como las de totalidad y efectividad. Así debe tratarse que la decisión sustancialmente sea lo más justa posible. Resolver esta situación conforme a los principios de igualdad y justicia, exige la instrumentación de formas complejas alejadas de los procedimientos lineales que acarrean resultados injustos.

Entendemos que pueden mitigarse algunos de los excesos que el sistema hipotecario produce sobre el deudor mediante una aplicación de la normativa existente que parta de la situación de inferioridad en la que se encuentra dicho deudor, y concretamente mediante un escrupuloso control por parte del secretario judicial de las costas presentadas por la entidad acreedora a efectos de tasación.

En la mayor parte de las ejecuciones hipotecarias el deudor no se persona en el procedimiento, y por tanto una vez que es adjudicado el bien inmueble objeto de ejecución, presentada que es por la entidad acreedora la solicitud de tasación de costas, aquel no la impugna pese al traslado que le es conferido. Ante esta situación el secretario judicial tiene una importante labor que llevar a cabo, exigiendo un estricto cumplimiento de las normas que regulan la tasación de costas, e interpretando las mismas en el sentido más favorable al deudor ${ }^{6}$, como parte no sólo más desfavorecida sino también en la mayoría de los casos no asistida técnicamente.

\section{PRÁCTICA DE LA TASACIÓN DE COSTAS.}

Es al secretario judicial a quien compete la función de liquidación de costas, en virtud de lo establecido en el art. 243 LEC, y su función no es meramente cuantificadora y liquidatoria, puesto que además, y como técnico en derecho que es, asume en principio una misión de decisión excluyendo las partidas indebidas y estudiando, en definitiva, la legalidad y exigibilidad de las minutadas?

En la práctica de una tasación de costas no son determinantes por sí solos ni la cuantía del proceso $^{8}$ ni los criterios del Colegio de abogados, precisamente por ser estos de carácter simplemente orientador ${ }^{9}$. A estos efectos ha de quedar claro que

\footnotetext{
${ }^{6}$ Sin duda el principio favor debitoris debe ser tenido en cuenta por el órgano judicial como principio orientador al interpretar la ley. El fundamento de esta regla es siempre una finalidad de justicia, ya que se propone restablecer el equilibrio entre las partes, porque presume que el deudor suele ser, en la mayoría de los casos, la parte más débil de la relación jurídica obligatoria. Castán Vázquez (1961, pp. 835-850), muestra la repercusión que el favor debitoris ha tenido en la legislación española, como así también en su jurisprudencia.

${ }^{7}$ SAP Badajoz, Sec. $3^{\text {a }}$, 30.10.2007 (ROJ: SAP BA 1008/2007; MP: Marina de la Cruz Muñoz Acero).

8 ATS, $1^{\mathrm{a}}$, 03.5.2011 (ROJ: ATS 4777/2011; MP: José Antonio Seijas Quintana). Martí Martí, (2011, p.3), pese a entender que el TS vacía de legitimidad a los baremos profesionales al admitir un criterio que proviene de la subjetividad concluye que "la doctrina del Tribunal Supremo es suficientemente clara, es el propio órgano judicial el que determinará lo que le ha costado al Abogado preparar su intervención en el proceso, las horas empleadas y la jurisprudencia que ha estudiado. Y todo ello para valorar económicamente su minuta a efectos de tasación".

${ }_{9}$ ATS, $1^{a}$, 02.10.2011 (ROJ: ATS 9569/2012; MP: Francisco Marin Castán).
} 
la función del secretario judicial no se puede limitar a recoger sin más la minuta de los profesionales, porque de ser así carecería de sentido este acto procesal que prevén y regulan los arts. 241 y ss. LEC. En el caso de la minuta de letrado, el secretario judicial ha de partir, para su inclusión en la tasación, de su acomodación a la ley, y respeto tanto a la cuantía del proceso, según previene el art. 253 LEC, como al límite impuesto por el art. 394.3 de dicha Ley Rituaria ${ }^{10}$.

La misión cuantificadora y liquidadora del secretario judicial en la tasación de costas, no sólo presenta aspectos meramente matemáticos y contables, sino que también asume una misión de decisión, que tiene su apoyo en las facultades que le confieren los arts. 243 y ss. LEC. Así puede no incluir en la tasación partidas justificadas por las partes y aportadas por los que soliciten la tasación de costas, como pueden ser minutas de letrados no detalladas, o conceptos incluidos en minutas del procurador tales como bastanteos de poder, testimonio y desglose del mismo, etc ${ }^{11}$. No se puede aceptar, como algún sector doctrinal apunta, que el secretario judicial deba incluir en la tasación de costas las minutas de los profesionales cualesquiera que sea su forma o los conceptos que recoge en las minuta, no sólo porque el Tribunal Supremo admite que el secretario judicial rechace las minutas no detalladas ${ }^{12}$, sino porque el art. 243.2 LEC ordena que no se incluya en las tasaciones los derechos correspondientes a escritos, diligencias y demás actuaciones que sean inútiles, superfluas o no autorizadas por la ley, ni las partidas que no se expresen detalladamente o se refieran a honorarios que no se hayan devengado en el pleito, sin que tampoco se puedan incluir las costas de actuaciones o incidentes a que no se hubiera condenado expresamente a la parte que ha de pagarlas. Es decir, el secretario judicial no se limita a contabilizar o hacer una liquidación en el momento de la tasación de costas, sino que también tiene una función decisoria que llega hasta donde le marca la ley, cuyos límites legales son los establecidos en Tít. VII del Libro I LEC ${ }^{13}$. En este sentido, Vázquez Sotelo ${ }^{14}$ afirma que «las funciones que se atribuyen al secretario en la tasación de costas son funciones netamente judiciales ya que el secretario califica las partidas que se le presentan, las aprueba y las rechaza y en definitiva fija y cuantifica el importe de una condena establecida en una sentencia».

10 SAP Ciudad Real, Civil Sec. $2^{\text {a }}$, de 01.02.2001 (ROJ: SAP CR 126/2001; MP: José Arturo Fernández García)

${ }^{11}$ Cima García (1995, pp. 329-424).

12 STS, $1^{\mathrm{a}}$, 04.04.1988 (ROJ: STS 10056/1988; MP Cecilio Serena Velloso).

13 SAP Málaga, Civil Sec. 4ª 03.02.2011 (ROJ: SAP MA 145/2011; MP: Joaquín Ignacio Delgado Baena); y AAP Castellón, Civil Sec. $3^{a}$, 05.10.2006 (ROJ: AAP CS 608/2006; MP: María Victoria Petit Lavall).

${ }^{14}$ Vázquez Sotelo (1985, pp. 73-96). En dicho trabajo el autor señala que el secretario «desde hace más de un siglo, desde la vigencia de la Ley de Enjuiciamiento Civil, viene actuando en primer grado sin que se hayan producido problemas». 
A este respecto cabe señalar que el nuevo régimen jurídico, implantado por la Ley 13/2009, de 3 de noviembre, de reforma de la legislación procesal para la implantación de la nueva Oficina judicial (BOE nº 266, 4.11.2009), que atribuye al secretario judicial la resolución de la impugnación de la tasación de costas, supone confiar al mismo una función similar a la que tenían los tribunales, los cuales ejercían la misma con atención a determinadas pautas ponderativas. Contra el auto que anteriormente decidía el incidente no cabía recurso alguno ${ }^{15}$, afirmando a estos efectos el Tribunal Supremo, que si bien, en el régimen actual, contra la resolución procesal del secretario, cabe el recurso de revisión, y éste es un recurso ordinario, y devolutivo, que coloca al órgano que resuelve en segundo lugar en la misma posición procesal del que lo hace en primero, sin embargo, «habida cuenta el carácter y circunstancias de la función ponderativa que significa el cálculo de los honorarios, no cabe entender que es posible utilizar el recurso para sustituir la realizada por el secretario mediante un nuevo juicio de mejor criterio por el Tribunal, porque ello, además de no ajustarse a la propia naturaleza de la actividad procesal realizada, desvirtuaría la ratio de la reforma legal, pues, en lugar de simplificar la materia, se produciría el efecto contrario de multiplicar el trabajo de la oficina judicial, y probablemente, sin descargar de forma efectiva la carga del titular del órgano jurisdiccional $»^{16}$. Ello sin perjuicio de que mediante el recurso de revisión se pueda someter al control del Tribunal, además de las infracciones de índole procesal, los casos de arbitrariedad o de irracionabilidad, y dentro de ellos la desproporcionalidad, por cuanto afectan al derecho a la tutela judicial efectiva.

\section{CUANTÍA DEL PROCESO.}

Tanto los honorarios del letrado como los derechos del procurador son fijados tomando como referencia la cuantía del procedimiento, de ahí la importancia de este extremo en cuanto a la práctica de la tasación de costas. Cuantía que queda determinada $a b$ initio en el auto de admisión a trámite de la demanda, que en el caso de la ejecución hipotecaria equivale al auto despachando ejecución, quedando fijada definitivamente tras resolverse la oposición en su caso formulada, o tras la preclusión de dicho trámite. Realizada dicha concreción se produce una perpetuatio, una petrificación de este dato procesal que funciona sin alteración alguna en las demás etapas o grados jurisdiccionales ${ }^{17}$, alegando el Tribunal Su-

${ }^{15}$ Art. 246.3 LEC.

${ }^{16}$ ATS, $1^{\text {a }}$, 28.02.2012 (ROJ: ATS 2332/2012; MP: Xavier O'callaghan Muñoz).

${ }^{17}$ En este sentido Ruiz de la Cuesta Fernández (2010, p.3), sostiene igualmente que "uno de los efectos típicos de la determinación de la cuantía es el de la perpetuación de la jurisdicción, lo que supone, entre otras consecuencias, una suerte de petrificación de ese dato procesal que funcionará sin alteración alguna en las demás etapas o grados jurisdiccionales, lo que implica, entre otros aspectos, que no puede atenderse 
premo que «la cuantía de un procedimiento, si no existe controversia de las partes sobre dicho punto, queda definitivamente fijada en los escritos de demanda y de contestación, en virtud del principio de la perpetuatio jurisdictionis» ${ }^{18}$. La LEC eleva a la categoría de norma tales criterios doctrinales al establecer en su art. 253.1 II que «La alteración del valor de los bienes objeto del litigio que sobrevenga después de interpuesta la demanda, no implicará la modificación de la cuantía ni la de la clase de juicio».

Ahora bien, en los procedimientos de ejecución hipotecaria, al tratarse de una reclamación de cantidad, la determinación del valor de lo reclamado no plantea problema alguno, siendo la cuestión a dilucidar si la cuantía viene determinada por la cantidad reclamada en concepto de principal, o si deben incluirse también en ella las sumas reclamadas en concepto de intereses y costas de ejecución, y que conforme a lo antes expuesto con carácter general se presupuestan en el 30\% de dicho principal.

Entendemos que la cuantía del asunto debe ser la fijada en la demanda como importe del principal reclamado, de acuerdo con lo preceptuado en los arts. 251 y 252 LEC, por cuanto que conforme a lo establecido en el párrafo segundo de este último art. "para la fijación del valor no se tomarán en cuenta los frutos, intereses o rentas por correr, sino sólo los vencidos», añadiendo seguidamente que «tampoco se tomará en cuenta la petición de condena en costas». Por tanto no pueden tenerse en cuenta las cantidades presupuestadas y pendientes de ulterior liquidación que en los procedimientos de ejecución hipotecaria se postulan para intereses y costas, pues la expresada regla del art. 252 LEC diferencia entre los intereses ya vencidos, computables para la determinación de la cuantía, y los no vencidos, que no cabe tener en cuenta a estos efectos, a los que habrá de asimilarse el importe de las costas, tanto porque el derecho a hacerlas efectivas solo nace posteriormente según el resultado del proceso, como por cuanto que ninguna regla permite su inclusión a estos efectos $^{19}$. Exclusión que además resulta razonable, ya que desde luego no es lógico que para hallar la base que ha de servir para fijar honorarios y derechos se incluyan ya en ella precisamente esos derechos que se pretenden calcular.

a una eventual revalorización posterior o depreciación a lo largo del tiempo del valor del objeto litigioso".

18 SSTS, $1^{\text {a }}$, 27.06.1992 (ROJ: STS 13639/1992; MP Matías Malpica y González Elipe) y 25.01.2001 (ROJ: STS 381/2001; MP José Manuel Martínez-Pereda Rodríguez), entre otras muchas. En igual sentido SAP Madrid, Civil Sec. 14ª , 28.07.2011 (ROJ: SAP M 11649/2011; MP: Juan Uceda Ojeda).

19 Este criterio es el mantenido con carácter general, tanto para determinar los derechos de los procuradores como los honorarios de letrados, en la STC 93/1993, Sala $1^{a}$, de 22 de marzo (BOE nº 100, de 27.04.1993; MP: Ponente: Rafael de Mendizábal Allende) y por la Jurisprudencia del Tribunal Supremo, AATS, $1^{a}, 26.09 .2006$ (ROJ: ATS 12529/2006; MP Román García Varela), 16.04.2002 (ROJ: ATS 4617/2002; MP José de Asís Garrote), y 18.12.2001 (ROJ: ATS 2370/2001; MP José de Asís Garrote) entre otros. Criterio que asimismo es seguido también por numerosas Audiencias Provinciales, así SAP Asturias, Civil Sec. 5ª 24.10.1997 (ROJ: SAP O 269/1997, MP: Francisco Luces Gil); AAP Asturias, Civil Sec. $7^{\text {a }}$, 12.07.2002 (ROJ: AAP O 269/2002; MP: Julián Pavesio Fernández); y SAP Zaragoza, Civil Sec. 2ª 28.12.2000 (ROJ: SAP Z 3393/2000, MP: Francisco Acín Garós), entre otras. 
Por tanto, presentada la solicitud de tasación de costas el primer extremo que debe verificar el secretario judicial, sin necesidad de que dicho extremo sea alegado por la parte ejecutada en trámite de impugnación, es que la minuta del letrado y los derechos del procurador hayan sido calculados partiendo de la cuantía del procedimiento fijada en la forma expuesta, y en caso contrario, proceder a su adecuación proporcional a la cuantía correctamente determinada, o bien conceder el oportuno plazo para subsanar dicho defecto procesal.

\section{MINUTA DEL LETRADO.}

El art. 243.2 LEC exige que el letrado, cuando solicite la práctica de la tasación de costas, deba presentar «minuta detallada», y la STC n 28/1990, 2ª 26.02.1990 (BOE n 70, de 22.03.1990; MP: Eugenio Díaz Eimil), entre otras en igual sentido, exige que «las partidas deben detallar los conceptos que las integran, de forma tal que garanticen a la parte condenada en costas el conocimiento que precisa para ejercer plenamente su derecho de contradicción, y expresar por separado la cuantía de los derechos y honorarios correspondientes a cada concepto minutado, siendo por tanto procedente rechazar las minutas que, sin más especificación, se limitan a hacer referencia genérica a partidas arancelarias, así como aquellas que se reducen a señalar la cuantía global de la minuta, sin singularizar la que corresponde a las partidas que la componen». Esta postura es reiterada, entre otras, por STS, $1^{\text {a }}$, 05.05.1992 (ROJ: STS 19581/1992; MP Luis Martínez Calcerrada Gómez), conforme a la cual «la obligatoriedad del detalle de la minuta tiene como fin conocer los trabajos realizados y su ajuste y comprobación con los trámites que dan derecho a incluir la minuta del letrado en la tasación de costas para evitar que se giren conceptos inadecuados, no realizados o fruto sólo del interés particular de la parte».

No obstante también hemos de destacar que más modernamente ${ }^{20}$ el Tribunal Supremo atenuó dichas exigencias en el sentido de «que si bien es cierto que la más reciente doctrina de esta Sala tiene proclamado que el art. 423 LEC exige la aportación de minuta detallada, no es necesaria la consignación de la cuantía concreta asignada a cada concepto, pues ésta ha de resultar, indudablemente, del aspecto proporcional asignable a cada una de las correspondientes normas; debiendo precisarse que la expresada doctrina se refiere obviamente a aquellos supuestos en que los conceptos comprendidos en la minuta respectiva sean todos ellos procedentes y reclamables, pero no aquellos otros en que se minuta por un concepto improcedente, pues en dicho caso resulta imposible determinar qué cantidad, dentro de la global, y única reclamada, debe ser eliminada o detraída, en cuanto correspondiente al concepto indebidamente minutado».

${ }^{20}$ STS, $1^{\mathrm{a}}, 12.07 .1994$ (ROJ: STS 18160/1994; MP Francisco Morales Morales). 
Resulta relativamente frecuente que las minutas presentadas hagan referencia, sin más, al criterio que las normas orientadoras de los colegios de abogados contienen para los procesos de ejecución forzosa ${ }^{21}$. Sin embargo pese a que en la mayor parte de los supuestos nos encontramos ante un procedimiento hipotecario en el que no ha existido oposición e incidencia alguna, el letrado fija su minuta aplicando el porcentaje máximo establecido, sin justificar los motivos por los que aplica tal porcentaje. Esta circunstancia impide a la parte ejecutada poder conocer tales razones y por ende disponer de argumentos para impugnar la misma. Conforme ya hemos expuesto, la minuta ha de ser adecuada a las circunstancias concurrentes en el pleito y al grado de complejidad del asunto, y por consiguiente si el letrado que presenta la minuta aplica el porcentaje máximo de las normas orientadoras, deberá indicar las circunstancias por las que se fija de esta manera su minuta, sin que sea dable que el secretario judicial haga de mero observador a la espera de una impugnación que en la mayor parte de las veces no se articulará habida cuenta de la situación de rebeldía en la que se encuentra la parte ejecutada.

Es evidente que el espíritu de la ley al exigir el detalle de la minuta es facilitar su control por los órganos judiciales, evitando así la inclusión de partidas superfluas y no exigidas por la ley, y la consiguiente indefensión que se produciría cuando el condenado al pago de las costas desconociese los conceptos incluidos en aquella minuta y, por tanto, no contase con criterios claros para poder impugnarla. No se trata de dar a las palabras «minuta detallada» una significación rígida que exija siempre una especial separación y cuantificación de los distintos trabajos que configuran la minuta del letrado, individualizando todas y cada una de las intervenciones que ha tenido en el procedimiento, sino como expresión de la voluntad del legislador de que se indique de modo claro el trabajo desarrollado por el que se minuta y la cuantía económica que se valora.

Sobre esta base, si bien es fácil comprender el cambio de criterio que ha sufrido la doctrina del Tribunal Supremo en estos últimos años ${ }^{22}$, admitiendo que aunque es necesario determinar el trabajo realizado por el que se minuta, no es necesario que se

${ }^{21}$ Los «Criterios del Colegio de abogados de Madrid en la emisión de sus dictámenes sobre honorarios profesionales a requerimiento judicial», aprobados por la Junta de Gobierno, en sesión de 28 de octubre de 2008 en su número 52 relativo a la ejecución forzosa, dispone: «Si no hubiese oposición, podrá aplicarse hasta el $75 \%$ de la Escala sobre la cuantía por la que se despache ejecución y se tramite completa la vía de apremio, recomendado $300 €$. Si se suscitara oposición, podrá aplicarse hasta el 100\% de la Escala sobre la cuantía por que se despache ejecución y se tramite completa la vía de apremio, recomendado $600 €$. Dicho Colegio de abogados en su Catálogo de preguntas frecuentas, abril 2012, p. 6, en relación con el referido Criterio 52 de las normas orientadoras dispone que «La delimitación del porcentaje (puesto que en ambos casos se establece "HASTA" el 75\% o el 100\%) se realizará ponderando circunstancias tales como el importe de las cantidades por las que se despacha ejecución, el trabajo efectivamente realizado por el letrado, el tiempo transcurrido desde el inicio de la ejecución, etc.».

22 SSTS, $1^{\mathrm{a}}$, 10.03.1993 (ROJ: STS 18728/1993; MP Francisco Morales Morales); 21.06.1995 (ROJ: STS 3636/1995; MP Luis Martinez-Calcerrada Gómez); y 30.12.1998 (ROJ: STS 8030/1998; MP Francisco Morales Morales). 
cuantifiquen y valoren las distintas intervenciones procesales de modo independiente cuando las mismas no se encuentran valoradas separadamente por las normas o criterios del Colegio de Abogados o, aunque así fuere, cuando pueda obtenerse la cuantía de cada una de ellas del aspecto proporcional asignable a cada una de las actuaciones en la correspondiente norma orientadora, la decisión debe tomarse determinando si con los datos contenidos en la minuta la parte condenada al pago puede conocer si estamos ante un trabajo profesional necesario, no superfluo, para la defensa de los intereses del cliente dentro del procedimiento y pueda saber con unas simples operaciones matemáticas, tras analizar las normas y criterios del Colegio de abogados, si la cuantía se ajusta a los honorarios orientativos fijados por el mismo ${ }^{23}$.

Por tanto no puede considerarse que la minuta cumpla la exigencia de detalle pedida si no concreta qué actividad ha sido desarrollada por el profesional. Detallar no significa cuantificar las actuaciones realizadas, pero sí concretar las actuaciones jurídicas realizadas en cada caso para así poder valorar si lo minutado ha sido o no ejecutado y útil.

La interpretación que se ha venido haciendo de la expresión «minuta detallada», por parte del Tribunal Supremo, no es razón para negar que se le pueda exigir a la parte que detalle, porque ello está previsto en la norma, y en ningún caso lo que ha resuelto aquél es que no se pueda exigir que se cumpla la norma, que es algo totalmente distinto. Pero además habría que estar a cada caso concreto, tanto es así, que el propio Tribunal Supremo cuando no se ha detallado y se ha minutado de forma global conforme a la norma colegial ha resuelto en el sentido de no proceder el total minutado si alguna partida no se había ejecutado. Es decir, haciendo uso de una interpretación amplia se admite que se pueda detallar por remisión a normas colegiales sin definir actuaciones judiciales, pero ello no se debe confundir con cuantificar las mismas. Ahora bien, si alguna actividad no se realizó y está incluida en el global de la norma, la consecuencia es el rechazo entero de la minuta, porque el tribunal no puede concretar qué actuaciones sí y cuáles no han sido realizadas. Ésta es la consecuencia del uso de ese criterio que admite el Tribunal Supremo pero sin rechazar que pueda el órgano judicial exigir que se detalle.

Si el criterio orientador aplicado por el letrado permite aplicar hasta un determinado porcentaje máximo de la escala contenida en normas orientadoras del respectivo Colegio de abogados, desde luego no puede aplicarse dicho porcentaje máximo sin más, sino que habrá que justificar al menos cuáles son las circunstancias por la que se minuta de esta manera y no aplicando el importe mínimo o siquiera medio establecido. Las minutas así redactadas ningún concepto jurídico utilizan, se ignora qué actividad han realizado. Resulta un hecho evidente que alguna actuación tuvieron que realizar para llegar a este trámite, pero cuáles, no se pue-

23 AAP Madrid, Civil Sec. 21ª, 11 .04.2007 (ROJ: AAP M 5110/2007; MP: Rosa María Carrasco López); y SAP Madrid, Civil Sec. 10ª 05.07 .2006 (ROJ: SAP M 9447/2006; MP: Ángel Vicente Illescas Rus). 
de saber, porque no lo indica el letrado, que es a quien le corresponde concretarlo jurídicamente, ni se puede deducir de la indicación de la norma del Colegio dada su globalidad. Con la trascripción de la norma prevista para la ejecución y la reseña de la escala, no se cumple la exigencia de detalle, primero porque la norma no hace esa remisión, y segundo, y sobre todo, por cuanto que la norma colegial no es detallada, sino genérica, porque parte de que toda la actividad jurídica se ha realizado, y por tanto se debe concretar cuál es de ese todo la actividad ejecutada, o en su caso, indicar que han llevado a efecto todas las actuaciones previstas en la misma.

La minutas así aportadas no detallan nada, pues no informan de las actuaciones judiciales realizadas y por las que reclaman honorarios, porque no se trata de exigirle al letrado que cuantifique cada una de ellas, pero sí que las indique para comprobar si llevaron a cabo o no todas las actuaciones que legalmente integran la vía de apremio. Las minutas así presentadas incurren en una indeterminación absoluta. Una cosa es que las normas orientadoras de honorarios se refieran, en los criterios ofrecidos, al importe que «por toda la tramitación» puede reclamarse y otra que la reproducción formularia, acrítica y mecánica de esta misma expresión satisfaga las exigencias legales, que no pueden ser ni modificadas ni dejadas sin efecto por convenciones o disposiciones de rango manifiestamente inferior o desprovistas de todo carácter normativo. La fijación de una cuantía única y global sin concretar pormenorizadamente cuáles hayan sido las actuaciones realizadas no permite conocer ni discriminar si se incluyen o no conceptos correspondientes a «escritos y actuaciones que sean inútiles, superfluas o no autorizadas por la ley (...) o que se refieran a honorarios que no se hayan devengado en el pleito».

Así las cosas es harto frecuente encontrar minutas por importe de 20.000 euros en un procedimiento de ejecución hipotecaria en el que no se produce ninguna incidencia, con el único fundamento de que la deuda reclamada asciende a 350.000 euros. Desde luego si tenemos en cuenta que la demanda de tal procedimiento no ha requerido ningún estudio especial, pues en la mayor parte de las ocasiones corresponden a un formulario tipo, que los trámites llevados a cabo en el mismo han sido el requerimiento de pago al deudor, el señalamiento de la subasta y su celebración, la consecuencia no puede ser otra que la exclusión total del importe de la minuta, habida cuenta de su falta de concreción de las circunstancias que justifican la aplicación del criterio orientador en su porcentaje máximo. Está claro que si el criterio orientador permite moverse en un porcentaje que va desde el $1 \%$ al $75 \%$ de la escala, este último porcentaje está prevenido para los supuestos no sólo de oposición, sino de existencia de incidencias que lo justifiquen. Y desde luego una ejecución hipotecaria sin oposición y ningún tipo de incidencia debería ser minutada en su porcentaje o cuantía mínima al efecto recomendado por las normas orientadoras.

Estos extremos, desde luego, no sólo pueden, sino deben, ser controlados de oficio por el secretario judicial, pues si bien el mismo no está facultado para moderar los honorarios del letrado ni calificar los mismos de excesivos, no se trata de 
una moderación, sino de cuidar que la minuta cumpla los requisitos establecidos por la norma, es decir que sea detallada a fin de que el deudor pueda conocer los conceptos por los que se le reclama la minuta, y así tener argumentos para impugnar la misma. Y aplicar el porcentaje máximo que permiten las normas orientadoras sin ningún tipo de explicación no cumple desde luego con el requisito mínimo de detalle, siendo la consecuencia necesaria la exclusión del importe total de la minuta en aplicación de la doctrina anteriormente expuesta.

Al igual que en los procedimientos ordinarios cabe minutar las distintas fases declarativas -alegaciones, prueba, conclusiones-, en la ejecución también puede diferenciarse una fase inicial de alegación, que se corresponde con la presentación de la demanda y que concluye con el despacho de la ejecución, y la fase puramente ejecutiva o de apremio, al margen de la existencia o no de una posible oposición. Tal diferenciación se refleja en la propia LEC en cuyo Libro III, de la ejecución forzosa y de las medidas cautelares, el título IV, dedicado a la ejecución dineraria, contiene cinco capítulos, diferenciando las distintas fases procesales, y un último destinado a las particularidades de los bienes hipotecados o pignorados. Por otra parte, los criterios orientadores de honorarios profesionales de los Colegios de abogados, no vinculantes al órgano judicial pero sí referente de una práctica profesional correcta, diferencian las dos fases ya indicadas de inicio de la ejecución y del procedimiento de apremio. En definitiva, si bien nadie duda que la ejecución hipotecaria tiende a que por la vía de apremio se realicen los bienes del deudor para proceder al pago del crédito del actor, nada obsta que en la redacción de la minuta de honorarios del letrado se diferencien las dos fases o actos en los que se desarrolla su actividad ${ }^{24}$.

\section{APLICACIÓN DEL LÍMITE DEL ART. 394.3 LEC.}

Conforme a lo dispuesto en el art. 243.2 LEC el secretario judicial al practicar la tasación tendrá en cuenta la reducción que, respecto de los honorarios de abogados y demás profesionales no sujetos a tarifa o arancel ${ }^{25}$, señala el art. 394.3 LEC $^{26}$. Reducción que hará de oficio, salvo que el Juez hubiera declarado la existencia de temeridad. Este apartado ha sido duramente criticado por la doctrina, manifestan-

${ }^{24}$ SAP Tenerife, Civil Sec. $3^{\text {a }}$, de 28.09.2010 (ROJ: SAP TF 2446/2010; MP: María del Carmen Padilla Márquez).

${ }^{25}$ Banacloche Palao (2000, p. 660), señala que los honorarios de abogados y peritos han de ser considerados conjuntamente, no separados.

${ }^{26}$ Art. 394.3 LEC cuando «se impusieren las costas al litigante vencido, éste sólo estará obligado a pagar, de la parte que corresponda a los abogados y demás profesionales que no estén sujetos a tarifa o arancel, una cantidad total que no exceda de la tercera parte de la cuantía del proceso, por cada uno de los litigantes que hubieren obtenido tal pronunciamiento». 
do RAMOS MÉNDEZ27 que tal reducción podría considerarse inconstitucional; la crítica de QUECEDO ARACIL ${ }^{28}$ se centra en que pugna con el sentido y fundamento de la condena en costas por razón del vencimiento, basado en la necesidad de que la tutela del vencedor sea completa. El Grupo parlamentario CIU planteo la enmienda 1173, que resultó rechazada, tratando de eliminar esta reducción porque entendía que perjudicaba a estos profesionales. Asimismo la forma en la que está redactado este apartado plantea para cierto sector de la doctrina la duda de si la reducción sólo afectaba a los supuestos litisconsorciales ${ }^{29}$.

Sin embargo la aplicación de este límite a los procesos de ejecución no es cuestión pacífica, existiendo al respecto dos posturas contrapuestas:

a) Aquella que partiendo de una interpretación literal de los arts. 394.4 y 539.2 LEC no considera aplicable este límite ${ }^{30}$.

Se fundamenta en que el art. 539 LEC establece un peculiar régimen a la hora de imponer las costas causadas, entendiendo que si bien la dicción del art. $243 \mathrm{LEC}^{31}$ no distingue según el origen del pronunciamiento condenatorio entre la fase declarativa y la de ejecución, el mismo impone al secretario la obligación de aplicar el límite del 394.3 LEC sólo cuando éste proceda. Obligación que no procede en los procedimientos de ejecución, pues en estos las costas tienen un tratamiento legal independiente y distinto, imponiéndose siempre al ejecutado que no ha cumplido voluntariamente la resolución judicial condenatoria, dando lugar a la vía de apremio, o a numerosas e innecesarias actuaciones procesales, por su falta de colaboración, generando los correspondientes gastos y costas, que siempre son de su cargo, sin necesidad de expresa imposición.

En definitiva, vienen a decir que si el legislador hubiera deseado que en el juicio ejecutivo operara la limitación que el art. 394.3 LEC prevé para los declarativos, lo hubiera dispuesto de manera expresa al regular los prin-

${ }^{27}$ Ramos Méndez (2000, p. 454).

${ }^{28}$ Quecedo Aracil (2000, p. 974).

${ }^{29}$ Banacloche Palao (2000, p. 661), señala que: «la ley especifica que se puede reclamar costas por cada uno de los litigantes que hubieran obtenido tal pronunciamiento. Aunque el precepto no lo aclare esta posibilidad sólo parece razonable cuando se ejerciten pretensiones diferentes».

${ }^{30}$ SAP Albacete, Civil Sec. 2ª 25.01.2010 (ROJ: SAP AB 123/2010, MP: Juan Manuel Sánchez Purificación); SAP León, Civil Sec. $2^{\mathrm{a}}$, 11.07.2008 (ROJ: SAP LE 836/2008, MP: Manuel Ángel Peñin del Palacio); SAP A Coruña, Civil Sec. 6a , 30.01.2006 (ROJ: SAP C 125/2006, MP: Ángel Pantín Reigada); SAP Cáceres, Civil Sec. 1ª 22.05.2007 (ROJ: SAP CC 422/2007, MP: Juan Francisco Bote Saavedra); SAP Ciudad Real, Civil Sec. 1a , 06.06.2007 (ROJ: AAP CR 408/2007, MP: María Pilar Astray Chacón); y SAP Barcelona, Civil Sec. 1ª , 31.10.2005 (ROJ: SAP B 6815/2005, MP: María Dolores Portella Lluch).

${ }^{31}$ Art. 243 LEC: «El secretario judicial reducirá el importe de los honorarios de los abogados y demás profesionales que no estén sujetos a tarifa o arancel, cuando los reclamados excedan del límite a que se refiere el apartado 3 del art. 394 y no se hubiese declarado la temeridad del litigante condenado en costas». 
cipios generales referidos a las costas de la ejecución que lleva a cabo en el art. 539 LEC, en donde dispone que las partes deberán satisfacer los gastos y costas que les correspondan conforme a lo previsto en el art. 241 de esta ley, tras lo cual no establece limitación alguna a la indicada obligación.

b) Aquella otra, cuyos fundamentos compartimos, que entiende que sí es de aplicación el límite del art. 394.3 LEC a los procesos de ejecución ${ }^{32}$. Se considera que este límite no contradice sino que complementa el art. 539 LEC, por su espíritu y finalidad, como lo corrobora el 243 LEC y las remisiones expresas al 394 efectuadas en sede de ejecución, aunque sea en incidentes (arts. 561, 603, 736 LEC).

Teniendo en cuenta que el art. 394 LEC contiene los principios y reglas generales sobre la condena en costas, aquellos aspectos de su normativa que no se encuentren recogidos en ningún precepto especial y que carezcan de regulación específica, como es el caso del límite cuantitativo de la condena establecido en el art. 394.3 LEC, que no se contempla ni se contradice de ningún modo en el art. 539.2 LEC, tienen plena vigencia y aplicación en toda clase de procesos, y en particular en los de ejecución. Además, el espíritu y finalidad que informa la limitación contenida en el citado art. 394.3 LEC, de reducir e imponer un límite máximo al importe de la condena en costas, respecto a los honorarios y partidas de los profesionales que no están no sujetos a una tarifa fija o arancel, para evitar que se puedan cometer abusos en la minutación a cargo de la parte condenada, tiene el mismo sentido y obedece a igual necesidad en los procesos declarativos que en los de ejecución, por lo que su aplicación a éstos se encuentra totalmente justificada. Más allá del rigor que supone ya para el ejecutado el art. 539.2 LEC, la interpretación contraria a la aplicación del límite del art. 394.3 LEC a los procesos de ejecución conduciría de hecho a imponer al ejecutado una sanción, encubierta y carente de respaldo legal. Es evidente que si el fundamento de la limitación del art. 394 LEC en la determinación de las costas debidas es evitar el abuso y el exceso en la minutación de honorarios al litigante vencido por la parte vencedora, ese criterio de justicia y de ponderación es igualmente aplicable en los procesos de ejecución.

Este razonamiento teleológico, se completa con una interpretación analógica del art. 561 LEC, que establece que el auto que desestime la oposición condenará

${ }^{32}$ En este sentido SAP A Coruña, Civil Sec. 4a , 23.07.2009 (ROJ: SAP C 2118/2009, MP: Carlos Fuentes Candelas); SAP Valladolid, Civil Sec. 1ª, 13.02.2009 (ROJ: AAP VA 13/2009, MP: José Ramón Alonso-Mañero Pardal); SAP Málaga, Civil Sec. 5a , 22.11.2006 (ROJ: SAP MA 2815/2006, MP: María José Torres Cuellar); SAP Baleares, Civil Sec. 5ª , 02.03.2005 (ROJ: SAP IB 320/2005, MP: Miguel Juan Cabrer Barbosa); y SAP Lugo, Civil Sec. 1ª, 21.12.2005 (ROJ: SAP LU 1171/2005, MP: José Antonio Varela Agrelo). 
en las costas de ésta al ejecutado conforme a lo dispuesto en el art. 394 LEC para la condena en costas en primera instancia, por lo que hace una remisión en bloque en el proceso de ejecución a la normativa que para las costas se establece en la fase declarativa.

No obstante lo anterior, la aplicación de este límite normalmente no suele plantear problema en los procedimientos de ejecución hipotecaria, habida cuenta de la cuantía elevada del principal reclamado, pero sí puede resultar de aplicación en los supuestos de rehabilitación del préstamo hipotecario, ya que en estos casos, en virtud de lo dispuesto en el art. 693.3 LEC, las costas «se calcularán sobre la cuantía de las cuotas atrasadas abonadas e intereses vencidos».

\section{EJECUCIÓN DE LA VIVIENDA HABITUAL.}

Conforme a lo ya expuesto, la referida Ley 1/2013 añade un apartado 1 bis al art. 575 LEC, limitando, en el supuesto de ejecución de vivienda habitual, la cantidad que puede exigirse al deudor hipotecario al 5 por cien de la cantidad que se reclame en la demanda ejecutiva.

Asimismo aquella ley añade un apartado tercero al art. $21 \mathrm{LH}$, que queda redactado en los siguientes términos: «En las escrituras de préstamo hipotecario sobre vivienda deberá constar el carácter, habitual o no, que pretenda atribuirse a la vivienda que se hipoteque. Se presumirá, salvo prueba en contrario, que en el momento de la ejecución judicial del inmueble es vivienda habitual si así se hiciera constar en la escritura de constitución».

Ahora bien, en ninguno de las escrituras de préstamo hipotecario actualmente en ejecución se recoge dicho extremo, y por tanto se plantea el problema de cuándo hemos de entender que el bien ejecutado tiene el carácter de «vivienda habitual», y con ello cuándo las costas quedan limitadas al 5\% de la cantidad reclamada.

Mediante Real Decreto 8/2011 de medidas de apoyo a los deudores hipotecarios, de control del gasto público y cancelación de las deudas de empresas y autónomos contraídas por las entidades locales, de fomento de la actividad empresarial e impulso de la rehabilitación y de simplificación administrativa (BOE n ${ }^{\circ}$ 161, 07.07.2011), se modificó el art. 671 LEC $^{33}$. En su Preámbulo exponía este Real Decreto que la situación específica del mercado inmobiliario en España plantea situaciones de especial dificultad para quienes contrajeron préstamos hipotecarios en los momentos de mayor valoración de los inmuebles y se encuentran ahora con la imposibilidad de satisfacer sus obligaciones de pago.

33 Que queda redactado en los siguientes términos: «Si en el acto de la subasta no hubiere ningún postor, podrá el acreedor pedir la adjudicación de los bienes por cantidad igual o superior al sesenta por ciento de su valor de tasación». 
Frente a esta situación el Gobierno consideró necesario medidas adicionales para la protección de las familias con menores ingresos, así como las reformas necesarias para garantizar que las ejecuciones hipotecarias no den lugar a situaciones abusivas o de malbaratamiento de los bienes afectados, manteniendo plenamente, sin embargo, los elementos fundamentales de garantía de los préstamos y con ellos la seguridad y solvencia de nuestro sistema hipotecario, y destacando que la protección económica, social y jurídica de la familia constituye uno de los principios rectores de la política social y económica ${ }^{34}$. Sin embargo el 31 de octubre de 2011 entró en vigor una nueva modificación de la materia mediante la Ley 37/2011, de 10 de octubre, de medidas de agilización procesal ( $\left.\mathrm{BOE} \mathrm{n}^{\circ} 245,10.10 .2011\right)$, en la cual se establecía un nuevo régimen jurídico para los supuestos en que el inmueble no sea la «vivienda habitual» del deudor ${ }^{35}$. Todo ello sin establecer qué debe entenderse por tal expresión. Concepto que, en relación esta vez con las costas procesales, es nuevamente introducido en la LEC por la meritada Ley $1 / 2013$, sin que tampoco se establezcan los presupuestos que han de concurrir para calificar el inmueble objeto de ejecución como «vivienda habitual».

Así las cosas, el régimen jurídico aplicable a la tasación de las costas derivadas del proceso de ejecución hipotecaria es distinto atendiendo a si el bien ejecutado se trata de vivienda habitual o no. Esta variación del régimen jurídico atendiendo al criterio de vivienda habitual plantea múltiples dudas de aplicación, dado que el procedimiento de ejecución hipotecaria no prevé un trámite para su determinación. Por ello deberemos tener al efecto los siguientes extremos:

- El procedimiento no debería llegar a subasta sin tener ese dato, que sería conveniente publicar en el edicto de convocatoria de la misma. Si la parte ejecutante considera que el inmueble no tiene el carácter de «vivienda habitual» debería solicitar la declaración de dicho extremo con anterioridad al señalamiento de la subasta.

- En la ejecución hipotecaria, sujeta a reglas procesales especiales, se estará al contenido de la inscripción en el Registro de la Propiedad, habiendo de recordar que la inscripción del domicilio designado a efectos de notificaciones tiene carácter preceptivo. Solo se atenderá, como criterio prioritario, al lugar en que se practica el requerimiento de pago cuando en la escritura se haya fijado para el mismo un domicilio distinto al de la finca hipotecada.

\footnotetext{
${ }^{34}$ En base a estos principios se elevó al 60\% del valor de tasación la cantidad en la que el ejecutante podía adjudicarse el bien inmueble, eliminando la posibilidad de hacerlo «por la cantidad que se le debe por todos los conceptos». Esta última previsión legal permitía al ejecutante con una deuda pequeña, quedarse un inmueble cuyo valor de tasación era muy superior.

${ }^{35}$ En tal caso volvemos a la adjudicación al ejecutante por el 50\% del valor de tasación o la cantidad que se debe por todos los conceptos.
} 
- Corresponde a la ejecutante siguiendo el criterio de la buena fe procesal, acreditar que la vivienda hipotecada y designada como domicilio a efectos de notificaciones, extremo inscrito debidamente en el Registro de la Propiedad hemos de insistir, no constituye la vivienda habitual de la ejecutada. Dicho carácter no puede inferirse sin más, ni del resultado negativo del requerimiento de pago intentado en dicho domicilio, ni de su empadronamiento en un lugar distinto, por cuanto que vivienda habitual es un concepto jurídico distinto a la residencia, que puede tener un carácter temporal. $\mathrm{Al}$ respecto hemos de hacer referencia al concepto de vivienda habitual a efectos tributarios contenido en el Real Decreto 439/2007, de 30 de marzo, por el que se aprueba el Reglamento del Impuesto sobre la Renta de las Personas Físicas (BOE ${ }^{\circ} 78,31.03 .2007$ ), que en su art. 54 dispone que con carácter general se considera «vivienda habitual» del contribuyente la edificación que constituya su residencia durante un plazo continuado de, al menos, tres años. No obstante, se entenderá que la vivienda tuvo el carácter de habitual cuando, a pesar de no haber transcurrido dicho plazo, se produzca el fallecimiento del contribuyente o concurran otras circunstancias que necesariamente exijan el cambio de domicilio, tales como celebración de matrimonio, separación matrimonial, traslado laboral, obtención del primer empleo, o cambio de empleo, u otras análogas justificadas.

En caso de duda, en virtud del art. 1289 del Código Civil, teniendo en cuenta la mayor reciprocidad de intereses, deberá presumirse la característica de «vivienda habitual» del deudor en el caso de no tener la plena certeza del hecho.

En definitiva, si en la escritura de préstamo hipotecario, formalizada con anterioridad de la entrada en vigor de la Ley 1/2013, que sirve de título a la ejecución, se recoge de forma expresa como domicilio a efectos de notificaciones el de la propia finca hipotecada, tal extremo constituye una presunción iuris tantum de constituir la «vivienda habitual» del demandado. Es cierto que en muchos casos el requerimiento de pago en dicha vivienda resulta negativo, siendo precisamente tal extremo lo que justifica la notificación edictal que al efecto es llevada a $\mathrm{cabo}^{36}$, pero ello no significa que el ejecutado no resida en la vivienda objeto de apremio, pues el mismo está en su derecho de rehusar o ignorar las notificaciones que se le dirijan al domicilio indicado. La parte ejecutante no puede pretender que el ejecutado pierda la ventaja de calificar el bien hipotecado como «vivienda habitual», si pese a constar en la escritura de préstamo hipotecario que el domicilio indicado en la misma a efectos de notificaciones es la vivienda hipotecada -circunstancia que prima facie otorga a la misma el carácter de habitual-, se des-

${ }^{36}$ Art. 686.3 LEC: «Intentado sin efecto el requerimiento en el domicilio que resulte del Registro, no pudiendo ser realizado el mismo con las personas a las que se refiere el apartado anterior, se procederá a ordenar la publicación de edictos en la forma prevista en el artículo 164 de esta ley». 
preocupa de manera absoluta de toda acreditación al respecto antes de solicitar el señalamiento de la subasta. El acreedor ejecutante no puede pretender desvirtuar la presunción contenida en la escritura pública por el mero hecho de que el requerimiento de pago haya sido negativo en el referido domicilio, y obtener de esta manera una ventaja económica, mayor aún de la que la ley de permite, con claro abuso de derecho.

Por tanto, aun cuando la notificación en el domicilio indicado en la escritura de préstamo hipotecario resulte negativa, de dicho extremo no puede concluirse taxativamente ni que el ejecutado no resida en el mismo, ni la fecha desde la que en su caso no reside, pues ha de tenerse en cuenta que la vivienda habitual no pierde su carácter por el mero hecho de que su morador se ausente de la misma durante un periodo de tiempo.

\section{APLICACIÓN DEL IVA.}

\subsection{Repercusión.}

Es doctrina jurisprudencial consolidada de la Sala $1^{\text {a }}$ del Tribunal Supremo ${ }^{37}$, la que determina que es preciso incluir el IVA en la tasación de costas, pues si bien el sujeto pasivo de dicho impuesto es la persona que actúa profesionalmente, por tratarse de un impuesto de naturaleza indirecta que grava como hecho imponible las operaciones en el desarrollo de la actividad profesional al repercutirse íntegramente aquel sobre la persona para quien se realizó el servicio o mandato, resulta lógico entender que cuando la contraparte sea condenada al pago de las costas deba incluirse este concepto, por estar endosado el IVA al importe de los honorarios o derechos que ha de cobrar quien preste el servicio profesional. Ello quiere decir, que ha de abonarlo quien pagó finalmente el concepto de principal de dichos honorarios o derechos del que el referido impuesto es un simple complemento accesorio Todo lo cual es aplicable no sólo a los honorarios del letrado sino también a los derechos del procurador ${ }^{38}$.

37 SSTS, $1^{\text {a }}$, 13.02.2001 (ROJ: STS 953/2001; MP: Ignacio Sierra Gil de la Cuesta); 30.12.1986 (ROJ: STS 7849/1986; MP Matías Malpica González Elipe); 20.03 .1996 (ROJ: STS 7816/1996; MP Pedro González Poveda); 27.03.2000 (ROJ: STS 2475/2000; MP Alfonso Villagómez Rodil); 05.07.2001 (ROJ: ATS 1484/2001; MP Pedro González Poveda); y ATS, 1ª , 01.04 .2005 (ROJ: ATS 3769/2005; MP Jesús Corbal Fernández), entre otras muchas. Esta postura es asimismo la seguida por la mayoría de la doctrina: Font Serra (2000, p.1574) Calvo Sánchez (2001, pp. 73-119).

${ }^{38}$ STS, $1^{\text {a }}$, 30.11 .2006 (ROJ: STS 7537/2006; MP Encarnación Roca Trías). En el mismo sentido, dice la STS, $1^{\text {a }}$, 14.01.2009 (ROJ: STS 1/2009; MP Ignacio Sierra Gil de la Cuesta): «Es tan repetida y pacífica la doctrina de esta Sala que establece que el IVA se debe incluir en la tasación de costas, que con solo ver las sentencias de esta Sala de 9 de diciembre de 2004, 1 de abril de 2005 y 20 de septiembre de 2006, se desprende paladinamente la carencia de base del motivo». 
En este sentido se pronuncian asimismo tanto la Sala de lo Penal ${ }^{39}$ como la de lo Social ${ }^{40}$, pero tal criterio es rechazado por la Sala de lo Contencioso Administrativo ${ }^{41}$, que sostiene que la tasación de costas alcanza exclusivamente a los honorarios del letrado y derechos y suplidos de los procuradores, siendo ajena a la misma toda cuestión relativa a la procedencia o no de la repercusión del IVA que sea consecuencia de la previa y definitiva tasación de costas, aclarando que cualquier controversia que se suscite sobre repercusión o retención de tributos debe sustanciarse y resolverse siguiendo los procedimientos administrativos establecidos. Ahora bien ello no implica que los letrados y procuradores no vengan obligados, por imperativo del art. 88 de la Ley 37/1992, de 28 de diciembre, del Impuesto sobre el Valor Añadido (BOE n 312, de 29.12.1992), a repercutir en su minuta el IVA correspondiente, separadamente de las cantidades reclamadas en concepto de honorarios y derechos. Cuestión ésta distinta a la de que sobre tal repercusión la Sala haga una declaración con la fuerza propia de un pronunciamiento judicial, ya que, como queda dicho, si surgiera contienda entre los sujetos implicados -sujeto pasivo del impuesto y quién debe soportarlo por venir obligado al pago-, la misma debe ser resuelta por la Administración y no por los órganos jurisdiccionales, que no pueden actuar preventivamente en esta materia, ni en ninguna otra de índole administrativa. Sin perjuicio de lo anterior, el sujeto pasivo del IVA, el letrado y procurador en este caso, viene obligado a repercutir su importe sobre la persona para quien se realiza la operación gravada que, en virtud de la condena en costas, no hace sino obtener el reintegro de lo abonado de quien resulta vencido en el proceso. En definitiva se trata de reintegrar al litigante que obtiene una sentencia favorable con condena en costas, por parte de quien resulta condenada en tal concepto, los gastos por aquél realizados. Consecuencia de lo anterior es que dicha Sala no se pronuncie sobre la repercusión de IVA, y estime

${ }^{39}$ AATS, $2^{\text {a }}$, 19.10.2001 (ROJ: ATS 7882/2001; MP Roberto García-Calvo Montiel) y 07.11.2001 (ROJ: ATS 10150/2001; MP Diego Antonio Ramos Gancedo).

40 AATS, 4a , 18.11.1998 (ROJ: ATS 3618/1998; MP Jesús González Peña); 23.12.1998 (ROJ: ATS 5547/1998; MP Luis Gil Suárez); y 09.02.2000 (ROJ: ATS 7662/2000; MP Luis Ramón Martínez Garrido): «que el impuesto correspondiente al cobro de honorarios o derechos, como contraprestación de un servicio profesional, bien entendido como un arrendamiento o como un mandato, está claramente incluido en lo que denomina el art. 1 de la Ley 30/1985, de 2 agosto , como impuesto de naturaleza indirecta al que están sujetas como hecho imponible las operaciones en el desarrollo de la actividad profesional (art. 3), que aun siendo el sujeto pasivo del mismo la persona física que actúa profesionalmente en la prestación del servicio (art. $15.1 .1^{\circ}$ ) ha de repercutirlo íntegramente sobre aquel para quien se realice la operación gravada". En consecuencia, si la condena en costas significa la satisfacción plena de lo que por este concepto tendría que pagar el vencido en juicio, no puede discutirse que al estar vinculado el impuesto al abono de los honorarios ha de abonarlos quien paga los mismos al ser el impuesto un complemento de los derechos profesionales».

${ }^{41}$ AATS, $3^{\text {a }}$, Sec. $6^{\text {a }}$ 26.11.2003 (ROJ: ATS 12491/2003; MP Agustín Puente Prieto) y Sec. $1^{\text {a }}$, 10.07.1998 (ROJ: ATS 2831/1998; MP Fernando Ledesma Bartret); y SSTS, 3 ${ }^{\text {a }}$, Sec. 6 ${ }^{\mathrm{a}}$, 22.10.1999 (ROJ: STS 6587/1999; MP Jesús Ernesto Peces Morate) y Sec. 6ª , 22.12.2004 (ROJ: STS 8379/2004; MP Santiago Martínez-Vares García). 
la pretensión de su exclusión de la tasación judicial impugnada, sin perjuicio del cumplimiento por las partes de la normativa fiscal en cuanto resulte procedente.

La Dirección General de Tributos en Consulta n ${ }^{\circ}$ 100/2005 de nueve de marzo, dispuso, que las cantidades que en concepto de costas judiciales se tasan a favor de una de las partes litigantes no tienen la consideración de contraprestación de operación alguna sujeta al IVA, puesto que la parte en favor de la cual se determina la percepción de dichos importes no efectúa ninguna entrega de bienes o prestación de servicio en favor de la parte condenada al pago de las citadas costas judiciales. Dichas costas judiciales corresponderán, generalmente, a los gastos incurridos en un procedimiento judicial por la parte en favor de quien se determine el cobro de las mismas. Por consiguiente, las cantidades que en concepto de costas judiciales se tasen en favor de una de las partes en un proceso judicial tienen para dicha parte el carácter de indemnización, y no constituyen por tanto la contraprestación de operación alguna gravada por dicho impuesto realizada por la parte que las satisface en favor de la parte que las percibe, no debiendo ni pudiendo por ello repercutir esta última a aquella cantidad alguna en concepto de impuesto sobre el valor añadido con ocasión del cobro de tales cantidades. Señalando asimismo que todo lo anterior sin perjuicio de la sujeción al IVA de los servicios que pudieran haberle sido prestados a la parte que ha de percibir las cantidades en concepto de costas judiciales por empresarios o profesionales que actúen en el ejercicio independiente de su actividad empresarial o profesional, con independencia del hecho de que sea precisamente el importe de tales servicios el que haya de tenerse en cuenta para determinar las costas judiciales que habrá de satisfacerle la otra parte en el proceso. En tal caso, los referidos empresarios o profesionales, en su condición de sujetos pasivos del IVA que gravaría los referidos servicios, estarían obligados a efectuar la repercusión de dicho impuesto sobre el cliente con el que han concertado la prestación de los servicios, destinatario de tales servicios, mediante la correspondiente factura expedida para este último. El cliente destinatario de los servicios y de la factura correspondiente a los mismos, está obligado a soportar la repercusión del impuesto que le efectúen los referidos empresarios o profesionales ${ }^{42}$.

\subsection{Límite del tercio de la cuantía del proceso.}

La aplicación del límite prevenido en el art. 394.3 LEC plantea el problema de la inclusión del IVA en su determinación. No estamos ante un asunto pacífico, pues como dice la SAP Cádiz, Civil Sec. 8a , 26 .03.2007 (ROJ: SAP CA 2136/2007; MP: Ignacio Rodríguez Bermúdez de Castro), «esta cuestión ha sido objeto de decisiones contradictorias por los Tribunales. Mientras que una línea incide más en que el IVA es un tributo que no forma parte de los honorarios y

\footnotetext{
42 En igual sentido BAYAS FERNÁNDEZ (2007, pp. 2-3), y BELSÚE MARTÍ́N (2006, pp. 1-3).
} 
que, aunque lo cobra el profesional, lo hace como mero recaudador, de tal modo que se configura como un concepto aparte de ese límite del tercio ${ }^{43}$, otra corriente valora especialmente la dicción del precepto, expresivo de que es la cantidad total a satisfacer la que no debe exceder de esa tercera parte, y, por ello, no cabe añadirle otras sumas suplementarias que superen ese límite» ${ }^{44}$.

Al efecto entendemos que el límite del tercio establecido en el art. 394.3 LEC no puede aplicarse con exclusión del IVA, ya que una cosa es la inclusión del citado impuesto en la tasación y otra bien distinta que se discuta, en el orden civil, el importe sobre el que se aplica, por cuanto el art. 394.3 LEC no habla de «minuta de honorarios» sino de la «parte que corresponda al abogado y demás profesionales que no estén sujetos a tarifa o arancel» y, bajo tal consideración debe entenderse ajustada a derecho la aplicación de la tercera parte a la minuta considerada en su conjunto, que es precisamente la parte que corresponde al abogado.

Otra exégesis nos llevaría a una polémica de imposible solución, pues el precitado artículo no hace ninguna distinción conceptual, sino que fija importes globales «para los abogados y demás profesionales que no estén sujetos a tarifa o arancel», lo que tiene lógica si pensamos que la finalidad del precepto es la de fijar un límite para las costas de cálculo sencillo y no la de calificar la intervención de cada profesional, los vínculos contractuales que puedan tener o, como es el caso, la condición de recaudador del IVA ${ }^{45}$.

A la interpretación literal de la norma, cuya finalidad parece clara en el sentido de impedir que, por uno y otro concepto, la condena al obligado al pago de las costas supere el límite de la tercera parte de la cuantía del proceso, se añaden otras dos razones, que pueden considerarse decisivas, y que expresa adecuadamente la SAP Asturias, Civil Sec. 4ª , 02.03.2006 (ROJ: SAP O 858/2006; MP: Francisco Tuero Aller). De un lado, que es reiterada la jurisprudencia que ha venido incluyendo el IVA correspondiente a los honorarios de letrado en las tasaciones de costas, como formando parte integrante de las mismas ${ }^{46}$; de tal modo que si ese IVA es una parte de las costas «de las que corresponden a los abogados», habrá de sujetarse al referido límite, en virtud del claro mandato legal, $\mathrm{Y}$ de otro lado, que también es pacífica la jurisprudencia expresiva de que el titular del crédito al pago

${ }^{43}$ SAP Barcelona, Civil Sec. 14 a , 10.10.2003 (ROJ: SAP B 5215/2003, MP: María Eugenia Alegret Burgues); SAP Córdoba, Civil Sec. 2a , 11.09.2002 (ROJ: SAP CO 1236/2002, MP: Juan Ramón Berdugo Gómez de la Torre); SAP Albacete, Civil Sec. 1ª, 21.05.2001 (ROJ: AAP AB 75/2001, MP: José García Bleda); y SAP Valencia, Civil Sec. 7ª 16.09.2004 (ROJ: SAP V 3901/2004, MP: María Filomena Ibáñez Solaz).

${ }^{44}$ En este sentido SAP Pontevedra, Civil Sec. 1a , 23.07.2009 (ROJ: SAP PO 2123/2009, MP: Francisco Javier Valdes Garrido).

45 SSTS, $1^{\text {a }}$, 26.11.2003 (ROJ: STS 7530/2003; MP Francisco Marín Castán); 05.07.2004 (ROJ: STS 4777/2004; MP Luis Martínez-Calcerrada Gómez); y 09.12.2004 (ROJ: STS 7956/2004; MP Pedro González Poveda), entre otras muchas.

46 Cita, entre otras, las contestaciones de 10 de diciembre de 1993 (0298-93), 28 de mayo de 1997 (1098-97), 22 de octubre de 1999 (1952-99), 24 de octubre de 2000 (1877-00). 
de las costas es la parte que venció en el pleito y obtuvo a su favor la condena a su abono, y no su letrado. Pues bien, aquél vencedor pagará a su abogado lo que éste le facture de acuerdo con lo que entre ellos tengan pactado y por los conceptos que procedan, de una u otra índole, pero únicamente podrá repercutir al vencido una suma que no exceda de ese tercio, sin que sea admisible que desglose lo abonado por IVA, cuando, como se dice, forma parte de esas costas, para luego aplicarlo a la suma resultante y así superar ese tercio.

\section{RETENCIÓN IRPF.}

Hasta el año 2005 la Dirección General de Tributos ${ }^{47}$ entendía que los honorarios a satisfacer a los abogados y procuradores por la parte condenada en costas tenían para aquellos la calificación de rendimientos de actividad profesional, y por tanto sometidos a retención. Sometimiento que entendía no se veía desvirtuado por la inexistencia de relación contractual entre aquellos profesionales y la parte condenada, pues el hecho determinante de la retención viene dado por la circunstancia de que un obligado al pago (la parte condenada en costas, en este caso) satisfaga como tal obligado rentas sujetas a retención. Sin embargo de diversas resoluciones del Tribunal Supremo ${ }^{48}$, que configuran la condena en costas como generadora de un crédito a favor de la parte vencedora y, por tanto, no perteneciente a quien la representa o asiste, llevan a la referida Dirección General a modificar el criterio expresado ${ }^{49}$, en el sentido de considerar que en los supuestos de condena en costas, al ser beneficiaria la parte vencedora, la parte condenada no está satisfaciendo rendimientos profesionales a los abogados y procuradores de la parte vencedora sino una indemnización a esta última, por lo que dicha parte condenada no está obligada a practicar retención sobre tales honorarios profesionales. Todo ello sin perjuicio del cumplimiento de la obligación de practicar la correspondiente retención sobre los rendimientos que satisfaga a sus abogados y procuradores la parte vencedora, en cuanto tuviera la condición de obligado a retener, conforme al art. 74 del Reglamento del Impuesto sobre la Renta de las Personas Físicas, aprobado por el Real Decreto 1775/2004, de 30 de julio (BOE del día 4 de agosto).

47 SSTS, $1^{\text {a }}$, 21.11.2000 (ROJ: STS 8499/2000; MP Antonio Gullón Ballesteros); 23.05.1996 (ROJ: STS 3117/1996; MP Teófilo Ortega Torres); 09.07.1992 (ROJ: STS 5645/1992; MP Teófilo Ortega Torres); 04.11.1991 (ROJ: STS 10505/1991; MP Gumersindo Burgos Pérez de Andrade); y 16.07.1990 (ROJ: STS 11153/1990; MP Ramón López Vilas).

${ }^{48}$ Consulta $n^{\circ} 100 / 2005$ de nueve de marzo.

${ }^{49}$ SSTS, $1^{\text {a }}$, 27.11.2001 (ROJ: STS 9264/2001; MP José de Asís Garrote); 23.05.1996 (ROJ: STS 3117/1996; MP Teófilo Ortega Torres); 15.02 .1996 (ROJ: STS 946/1996; MP Teófilo Ortega Torres); y 07.03.1988 (ROJ: STS 1591/1988; MP José Luis Albácar López). 


\section{LETRADO EMPLEADO DEL ACREEDOR.}

Sin duda la existencia de letrados adscritos a la asesoría jurídica de grandes empresas, como bancos y aseguradoras, que no perciben sus honorarios por servicios prestados en determinado procedimiento, sino que se integran en la plantilla laboral de dichas empresas y cobran sus emolumentos como cualquier otro asalariado, plantea problemas de articulación con la regulación de costas procesales, pues el crédito de costas que una parte ostenta frente a la otra en virtud de la condena lo es para el reembolso de determinados gastos causados en el proceso, entre ellos los de letrado, gastos que en el caso de los abogados de empresa, aunque innegables, son sin duda de muy difícil conocimiento en su concreto alcance. Sin embargo la cuestión ya ha sido abordada en distintas ocasiones por el Tribunal Supremo $0^{50}$ y en todas ha estimado que en la tasación de costas los honorarios de los letrados de estas empresas han de incluirse como los de cualquier otro letrado. Otro tanto sucede con la jurisprudencia menor de las Audiencias Provinciales ${ }^{51}$. Sintéticamente tales argumentos son que otra solución acarrearía un tratamiento injustamente discriminatorio de las personas naturales o jurídicas que pudieran acordar sistemas de retribución continuada de sus letrados asesores y que, por tal razón perderían las ventajas económicas que una eventual condena en costas a la parte contraria en el litigio les pudiera deparar.

El Tribunal Constitucional ${ }^{52}$ y el Tribunal Supremo ${ }^{53}$ afirman que la relación entre el cliente y su letrado es la de arrendamiento de servicio, que no afecta para nada al desarrollo del proceso, pues el titular del crédito privilegiado que origina la condena en costas es la parte contraria beneficiaria de la misma y no los profesionales que han representado o defendido y, por ello, la circunstancia de quién sea el concreto profesional que haya prestado sus servicios carece de incidencia alguna en la obligación de que la resolución judicial ha impuesto al condenado en costas. Por tanto es del todo indiferente cuál sea la relación que vincula al letrado con su cliente, ya la del abogado que actúa en ejercicio libre de la profesión y generalmente dentro de una relación contractual de arrendamiento de servicios, ya la funcionarial o estatutaria que vincula a los abogados del estado o contratados por los organismos públicos o los unidos

50 SAP Las Palmas de Gran Canaria, Civil Sec. $3^{a}$, 25.02.2009 (ROJ: SAP GC 529/2009, MP: Ricardo Moyano García); SAP Oviedo, Civil Sec. 7ª , 21.11.2002 (ROJ: SAP O 4388/2002, MP: Víctor Emilio Covián Regales); SAP Oviedo, Civil Sec. 1ª 18.10.2001 (ROJ: SAP O 4074/2001, MP: Guillermo Sacristán Represa); SAP Madrid, Civil Sec. 10ª 02.06 .2001 (ROJ: SAP M 8097/2001, MP: Ángel Vicente Illescas Rus); SAP Valladolid, Civil Sec. 1a , 14.05.1999 (ROJ: SAP VA 813/1999, MP: Miguel Ángel Sendino Arenas); SAP Valladolid, Civil Sec. 1ª 18.09.2000 (ROJ: SAP VA 1363/2000, MP: Mª Teresa González Cuartero).

${ }^{51}$ SSTC n ${ }^{\circ}$ 110/1993, Pleno, 25.03.1993 (BOE n 100, de 27.04.1993; MP: Fernando García-Mon y González-Regueral) y nº 28/1990, 2ª 26.02.1990 (BOE n 70, de 22.03.1990; MP: Eugenio Díaz Eimil).

52 SSTS, $1^{\text {a }}$, 15.02.1996 (ROJ: STS 946/1996; MP Teófilo Ortega Torres); 09.07.1992 (ROJ: STS 5645/1992; MP Teófilo Ortega Torres); y 16.07.1990 (ROJ: STS 5685/1990; MP Ramón López Vilas).

53 Guasp Delgado (1948, pp. 134 y ss). 
por una relación laboral o de empleo. Así las cosas, esta circunstancia no constituye obstáculo para que la parte que ha obtenido el pronunciamiento favorable en costas, y que es la verdadera titular del crédito que representa la condena a su pago por el vencido, pueda resarcirse de los gastos derivados de la actuación procesal de los letrados que les defienden. Dice a este respecto el Profesor Guasp ${ }^{54}$ : «después de determinar sobre quién pesa la obligación de pagar las costas en que consiste la condena, hay que saber quién tiene derecho a exigir el pago, o sea, quién ha de considerarse como el titular del crédito que corresponde a la obligación impuesta. Este titular es, siempre y en todo caso, la parte o partes contrarias a aquella o aquellas que fueron condenadas; la relación se establece, por tanto, entre los litigantes, y no entre los acreedores del que obtiene la condena y el condenado, los cuales podrán, en caso de que la parte no trate de hacer efectivo su derecho, ejercitar la acción subrogatoria del art. 1.111 CC, pero en un proceso independiente y no por la vía de la exacción de costas, dentro del proceso en que éstas se producen; así pues el letrado o el procurador de la parte que obtiene la condena en costas no podrá exigir el pago de sus honorarios de la condenada, puesto que no son acreedores directos de ella, sino de la parte a quien representaron o defendieron. Ni siquiera puede concederse esto por vía excepcional, como ocurre en otras legislaciones con la llamada "distracción de las costas". Por consiguiente, el hecho de la condena no altera inmediatamente la obligación que tiene una parte de pagar las costas que ha originado, sino sólo mediatamente, a través del derecho concedido a ésta para obtener la satisfacción correspondiente a la parte condenada». El propio Tribunal Constitucional, en su ya citada sentencia de 26 de febrero de 1990, sigue esta misma orientación, al decir en uno de sus fundamentos jurídicos que «el titular del crédito privilegiado que origina la condena en costas es la parte contraria beneficiaria de las mismas y no los profesionales que le han representado o defendido y, por ello, la circunstancia de que estos profesionales hayan recibido parcial o totalmente sus derechos y honorarios de la parte a quien han prestado sus servicios carece de incidencia alguna en la obligación de pago que la resolución judicial ha impuesto al condenado en costas».

Por tanto, la condición de empleado que pueda concurrir en el letrado respecto a la entidad ejecutante no es obstáculo para que minute honorarios, ya que el profesional lo que hace es arrendar sus servicios, y la tasación no se practica en beneficio de los profesionales que intervienen por cuenta del litigante vencedor, sino en beneficio de la parte, es una indemnización a esta por el coste que le supone el proceso. El titular del crédito privilegiado que origina la condena en costas es la parte contraria beneficiaria de la misma, no los profesionales que la representan, con lo que no hay obstáculo alguno para que la parte condenada cumpla con su obligación de pago, en el hecho de que el letrado tenga una relación laboral, funcionarial o de otro tipo con dicha beneficiaria.

\footnotetext{
${ }^{54}$ SAP Madrid, Civil Sec. 20a , 26.03.2010 (ROJ: SAP M 4163/2010, MP: José María Salcedo Gener).
} 
No obstante ello, desde nuestro punto de vista tal solución constituye un enriquecimiento injusto. Es indiscutible que a la entidad acreedora se le originan unos gastos por la actuación del letrado en la ejecución hipotecaria, como también lo es que dicha entidad tiene derecho al resarcimiento de estos gastos, y que el beneficiario de dicho derecho es tal entidad y no el letrado que interviene en el procedimiento. Pero no podemos olvidar que finalidad de la tasación de costas es fijar con arreglo a los criterios legalmente previstos el importe total de las costas en función de las actuaciones y gastos satisfechos por la parte acreedora de las mismas $^{55}$. En definitiva, la finalidad de la tasación de costas radica en que, quien ha tenido que acudir a un pleito, obteniendo una resolución favorable, se vea resarcido en los gastos que ello le ha ocasionado por la parte vencida, pero no la obtención de un lucro en dicho resarcimiento, pues éste debe ser equivalente a los gastos que su necesidad de acudir al proceso le hayan ocasionado, pero nunca la obtención de una ganancia, y resulta obvio que el importe de las costas no podrá ser superior a los gastos reales ocasionados.

Pues bien, si la entidad acreedora tiene contratado a su servicio un letrado para encargarse de todos o parte de los asuntos que dicha entidad haya de ventilar ante los órganos judiciales, resulta evidente que el gasto que le supone no equivale al importe de la tasación de costas calculada conforme a un baremo para profesionales liberales. Cuantificar su importe resultaría tan fácil como acreditar las horas de trabajo invertidas en el asunto y abonar las mismas proporcionalmente conforme al salario que el letrado percibe de la entidad ejecutante. De otra manera a la entidad acreedora se le hará pago de un importe muy superior al gasto que le ha ocasionado con la intervención del letrado en el asunto, entendiendo que tal extremo constituye un caso palmario de enriquecimiento injusto, pues es obvio que el importe de la tasación de costas aprobada es notoriamente superior al salario que la entidad ejecutante abona al letrado integrado en su plantilla por las horas empleadas en el asunto en cuestión.

\section{CONCLUSIONES.}

1.- Algunos de los excesos que el sistema hipotecario produce sobre el deudor pueden y deben mitigarse mediante un escrupuloso control por parte del secretario judicial de las costas presentadas por la entidad acreedora a efectos de tasación, superando las estrechas visiones del principio dispositivo en el ámbito de la justicia civil cuando el ejecutado se encuentra en rebeldía, y alejándose de los procedimientos lineales que acarrean resultados contrarios al principio de tutela judicial efectiva.

55 SAP Madrid, Civil Sec. 20ª 26.03.2010 (ROJ: SAP M 4163/2010, MP: José María Salcedo Gener). 
2.- La función de la tasación de costas no es fijar cuáles deben ser los honorarios del letrado de la parte ejecutante, sino determinar la carga que debe soportar el obligado al pago de las costas respecto de los honorarios del letrado de la parte contraria. A estos efectos no son determinantes por sí solos ni la cuantía del proceso ni los criterios del Colegio de abogados, debiendo tenerse en cuenta el trabajo efectivamente realizado, el tiempo de dedicación y estudio, las dificultades del supuesto concreto, y las cuestiones incidentales suscitadas.

3.- La cuantía del proceso hipotecario a tomar como referencia para la tasación de costas se limita al principal reclamado, sin que a tal efecto puedan incluirse las cantidades presupuestadas en concepto de costas e intereses de la ejecución.

4.- La reproducción formularia, acrítica y mecánica en la minuta del letrado de la norma orientadora del Colegio de abogados relativa a la ejecución no satisface las exigencias legalmente exigidas, que no pueden ser ni modificadas ni dejadas sin efecto por convenciones o disposiciones de rango manifiestamente inferior o desprovistas de todo carácter normativo. La fijación en la minuta de un importe único y global sin concretar pormenorizadamente cuáles hayan sido las actuaciones realizadas no permite conocer ni discriminar si se incluyen o no conceptos correspondientes a escritos y actuaciones que sean inútiles, superfluas o no autorizadas por la ley o que se refieran a honorarios que no se hayan devengado en el pleito, principalmente si la minuta asciende al porcentaje máximo permitido por los criterios orientadores del respectivo Colegio de abogados, y la consecuencia no puede ser otra que la exclusión de todo su importe en la tasación de costas.

5.- El límite del tercio prevenido en el art. 394.3 LEC no solamente es aplicable a los procesos de ejecución hipotecaria, sino que opera sobre la cuantía de la minuta presentada con inclusión del IVA.

6.- La indicación de la propia finca hipotecada como domicilio a efectos de notificaciones en la escritura de préstamo hipotecario formalizada con anterioridad de la entrada en vigor de la Ley $1 / 2013$, que sirve de título a la ejecución, constituye una presunción iuris tantum de que la misma tiene el carácter de «vivienda habitual» del demandado, y por consiguiente las costas derivadas de dicho proceso habrán de quedar limitadas a un 5\% de la cantidad reclamada.

7.- La finalidad de la tasación de costas es fijar su importe con arreglo a los criterios legalmente previstos en función de las actuaciones y gastos satisfechos por la parte acreedora, y no la obtención de un lucro. Por tanto si el letrado que ha actuado en defensa de la entidad acreedora es empleado de la misma, el importe de su minuta no puede ser calculado conforme a un baremo para profesionales liberales, sino con sujeción a criterios que permitan resarcir a aquella entidad el gasto efectivamente sufrido. 


\section{BIBLIOGRAFÍA.}

ALMAGRO NOSETE, José (1990), "La Jurisdicción", en José ALMAGRO NOSETE et al., Derecho Procesal, Parte General, Proceso Civil (1), Tomo I (Vol. II), Tirant lo Blanch, Valencia, pp. 73-85.

BANACLOCHE PALAO, Julio (2001), "Capítulo VIII. De la condena en costas (arts. 394-398)”, en Andrés DE LA OLIVA SANTOS/Luis María DIEZ-PICAZO GIMÉNEZ/Jaime VEGAS TORRES, Comentarios a la Ley de Enjuiciamiento Civil, Civitas, Madrid, pp. 651-657.

BAYAS FERNÁNDEZ, Guillermo (2007), "El IVA y el IRPF en la tasación de costas. Hacia una jurisprudencia completa", Diario La Ley, N 6795, Sección Doctrina, Año XXVIII, Ref. D-212.

BELSUÉ MARTÍN, José Luis (2006), "El IVA y el IRPF en la tasación de costas procesales" Diario La Ley, Nº 6469, Sección Tribuna, Año XXVII, Ref. D-107.

CALVO SÁNCHEZ, María del Carmen (2001) "El coste de la justicia: especial referencia a las costas en los procesos declarativos de la Ley 1/2000, de Enjuiciamiento Civil", Cuadernos de Derecho Judicial, CGPJ, n XV, pp. 73-119.

CASTÁN VÁZQUEZ, José María (1961), "El favor debitoris en el derecho español”, Anuario de Derecho Civil, T. IV, Madrid, pp. 835-850.

CIMA GARCÍA, Carlos (1995), "La ejecución en materia de costas", Cuadernos de Derecho Judicial, CGPJ, n XXV, pp. 329-424.

COMELLAS SALMERÓN, Manuel (1954), "La nueva reglamentación del secretario en la Administración de Justicia", Revista de Derecho Procesal, Madrid, julio-septiembre 1954, pp. 419-431.

FONT SERRA, Eduardo (2000), "Título VII. De la tasación de costas", en Antonio María Lorca Navarrete (director) Comentarios a la nueva Ley de enjuiciamiento Civil, Lex Nova, Valladolid, T. I, p. 1574.

GIMENO SENDRA, José Vicente (1995), "Las garantías constitucionales en el proceso y el secretario judicial dentro del marco del Consejo de Europa», Poder Judicial, n 38, pp. 253-260.

GUASP DELGADO, Jaime (1948): Comentarios a la Ley de Enjuiciamiento Civil, M. Aguilar, Madrid,

JIMÉNEZ DE PARGA Y CABRERA, Manuel (1985), "La fe pública como atributo del Estado", en Primeras Jornadas sobre la fe pública judicial, Colegio Nacional de Secretarios Judiciales, Barcelona, pp. 13-25.

LORCA NAVARRETE, Antonio María (1993), Organización judicial española y principios rectores del proceso español, Dykinson, Madrid.

MARTÍ MARTÍ, Joaquim (2011), "Las costas y gastos en el proceso. El principio de la proporcionalidad con el trabajo realizado y la incidencia del 
mismo en el resultado", Diario La Ley, N 7751, Sección Práctica Forense, Año XXXII, Ref. D-462.

MARTÍN OSTOS, José de los Santos (1986), "Funciones procesales del secretario judicial en la LOPJ", en Segundas Jornadas sobre la fe pública judicial, Colegio Nacional de Secretarios Judiciales, Alicante, pp. 43-72.

MORELL OCAÑA, Luis (1987), "El secretario judicial en la dinámica del proceso contencioso-administrativo", en La fe pública judicial (III Jornadas), Colegio Nacional de Secretarios Judiciales, Madrid, pp. 93-99.

OSSORIO Y GALLARDO, Ángel (1929), Bases para la reorganización judicial, Pueyo, Madrid.

PRIETO-CASTRO FERRANDIZ, Leonardo (1984), "El Rechtspfleger", en Libro homenaje a Jaime Guasp, Comares, Granada, pp. 475-491.

QUECEDO ARACIL, Pablo (2000), "Comentarios al art. 394", en Miguel Ángel FERNÁNDEZ-BALLESTEROS / José María RIFÁ SOLER / José Francisco ALLS GOMBAU: Comentarios a la nueva Ley de Enjuiciamiento Civil, Iurgium, Barcelona, p. 974.

RAMOS MÉNDEZ, Francisco (2000), Guía para una transición ordenada a la Ley de Enjuiciamiento Civil, Bosch, Barcelona.

RUIZ DE LA CUESTA FERNÁNDEZ, Soledad (2010), "Aspectos puntuales de la determinación de la cuantía”, Práctica de Tribunales, Nº 75, Sección Informe de Jurisprudencia.

RUIZ-GIMÉNEZ CORTÉS, Joaquín (1987), "El secretario judicial, garantía constitucional del ciudadano", en La fe pública judicial (III Jornadas), Colegio Nacional de Secretarios Judiciales, Madrid, pp. 13-21.

SAINZ DE ROBLES RODRÍGUEZ, Federico Carlos (1987), “¿Existe el Poder Judicial?", Revista jurídica Tapia, n 37, pp. 3-11.

VÁZQUEZ SOTELO, José Luis (1985), "La intervención del secretario judicial en el proceso", en Primeras Jornadas sobre la fe pública judicial, Colegio Nacional de Secretarios Judiciales, Madrid, pp. 73-96.

\section{ABREVIATURAS.}

$\begin{array}{ll}\text { AAP, AAAP } & \text { Auto/s Audiencia Provincial } \\ \text { Art(s) } & \text { Artículo/s } \\ \text { ATS, AATS } & \text { Auto/s del Tribunal Supremo } \\ \text { BOE } & \text { Boletín Oficial del Estado } \\ \text { CC } & \text { Código Civil } \\ \text { CE } & \text { Constitución Española } \\ \text { LEC } & \text { Ley de Enjuiciamiento Civil } \\ \text { LH } & \text { Ley Hipotecaria }\end{array}$


Javier Ángel Fernández-Gallardo Fernández-Gallardo

$\begin{array}{ll}\text { IVA } & \text { Impuesto sobre el Valor Añadido } \\ \text { IRPF } & \text { Impuesto sobre la Renta de las Personas Físicas } \\ \text { MP } & \text { Magistrado ponente } \\ \text { N }^{\text {o }} & \text { Número } \\ \text { p, pp } & \text { Página/s } \\ \text { ROJ } & \text { Repertorio Oficial de Jurisprudencia } \\ \text { SAP, SSAP } & \text { Sentencia/s Audiencia Provincial } \\ \text { Sec. } & \text { Sección } \\ \text { ss } & \text { Siguientes } \\ \text { STC } & \text { Sentencia Tribunal Constitucional } \\ \text { STS, SSTS } & \text { Sentencia/s Tribunal Supremo } \\ \text { T } & \text { Tomo } \\ \text { TC } & \text { Tribunal Constitucional } \\ \text { TS } & \text { Tribunal Supremo }\end{array}$

